\title{
Vocalizations of Amazon river dolphins (Inia geoffrensis): Characterization, effect of physical environment and differences between populations
}

\author{
Thiago Orion Simões Amorim, ${ }^{\text {a),b) }}$ Artur Andriolo, ${ }^{\text {b) }}$ and Sarah S. Reis \\ Laboratório de Ecologia Comportamental e Bioacústica, Departamento de Zoologia, Instituto de Ciências \\ Biológicas, Universidade Federal de Juiz de Fora, Rua José Lourenço Kelmer, s/n - Campus Universitário, \\ Bairro São Pedro, 36036-900 Juiz de Fora, Minas Gerais, Brasil
}

\author{
Manuel E. dos Santos \\ Marine and Environmental Sciences Centre, ISPA - Instituto Universitário, Rua Jardim do Tabaco, 34, \\ 1149-041 Lisboa, P-1149-041 Portugal
}

(Received 7 August 2015; revised 30 January 2016; accepted 22 February 2016; published online 24 March 2016)

\begin{abstract}
The vocal repertoire of the Amazon river dolphin and its geographic variations are still poorly known, especially in relation to ecological variables. Here the acoustic characteristics of low frequency pulsed vocalizations, with single or multiple pulses, recorded in two protected areas of the Amazon were described and differences in acoustic emissions related to water properties were analyzed. Both frequency and time parameters differ relative to abiotic condition of water turbidity. Changes in the animals' acoustic behavior might be due to differences in sound propagation between rich-sediment water and clear water. Geographic variation was found in frequency and time parameters, requiring further investigation. (C) 2016 Acoustical Society of America.
\end{abstract}

[http://dx.doi.org/10.1121/1.4943556]

[WWA]

Pages: 1285-1293

\section{INTRODUCTION}

There are several studies characterizing echolocation signals of Amazon river dolphin or boto, Inia geoffrensis (de Blanville, 1817) (e.g., Penner and Murchison, 1970; Norris et al., 1972; Evans, 1973; Kamminga, 1979; Wiersma, 1982; Kamminga et al., 1993; Verfuss et al., 1997). The echolocation clicks are characterized by ultrasonic pulses with frequencies ranging from 16 to $150 \mathrm{kHz}$ (Evans, 1973) and dominant frequency between 85 and $100 \mathrm{kHz}$ (Kamminga et al., 1993). Tonal signals have also been reported for this species. Ding et al. (1995) and Ding et al.(2001) found whistles with simple contours and frequency below $5 \mathrm{kHz}$; MayCollado and Wartzok (2007) described whistles modulated in broader frequency range of 5.30 and $48.10 \mathrm{kHz}$.

Caldwell et al. (1966) and Caldwell and Caldwell (1967) recorded captive animals and described 12 types of vocalizations grouping them into four categories: single intense clicks, echolocations clicks, jaw-snaps and burstpulsed signals. The last category was grouped into seven types: "squawk," “screech," "bark," "whimper," “crack," "squeal," and "squeaky squawk."

In several animal taxa, groups geographically separated may be discriminated by their acoustics emissions. In cetaceans, such differences have been considered useful in providing insights into the social organization and association patterns among individuals (Whitehead et al., 1998; Deecke

\footnotetext{
a)Electronic mail: tosabio@gmail.com

b) Also at: Instituto Aqualie, Avenue Dr. Paulo Japiassu Coelho n 714, Sala 206, Juiz de Fora, Minas Gerais 36033-310, Brazil.
}

et al., 1999; Miller and Bain, 2000; Yurk et al., 2002; Bazuá-Durán and Au, 2004).

Geographical differences (or macrogeographic variations) are associated with widely separated populations groups over long distances, which do not normally mix; while microgeographic variations are generally assigned to sounds emitted on a local scale among neighboring groups which can potentially intermix (Grimes, 1974; Krebs and Kroodsma, 1980; Conner, 1982; McGregor et al., 2000).

Geographic variations can provide valuable information since they may reflect adaptations to different ecological conditions (Marler, 1960; Ford, 1991), dispersal capabilities of species (Mundinger, 1982; McGregor et al., 2000) and the extent of isolation and genetic divergence between groups or populations (Lemon, 1966; Ford, 2002). In the context of ecology, water abiotic features affect acoustic communication. Sound attenuation and degradation act as environmental constraints on the process of communication (Wiley and Richards, 1982) since they may affect the detection and recognition of emitters by receiver animals (Bradbury and Vehrencamp, 1998; Lugli and Fine, 2003). Given that, it is relevant to investigate how environmental features might act in the evolutionary design of vocalizations and consequently in their biological function.

Most research on dolphin underwater emissions has been conduced in the marine environment (Weilgart and Whitehead, 1997; Stafford et al., 2001; Bazúa-Durán and Au, 2004; Morisaka et al., 2005; Au and Hastings, 2008; Azzolin et al., 2013), and there is still a scarcity of information regarding variation in dolphin acoustic production in freshwater environments. Variations in pulsed vocalizations 


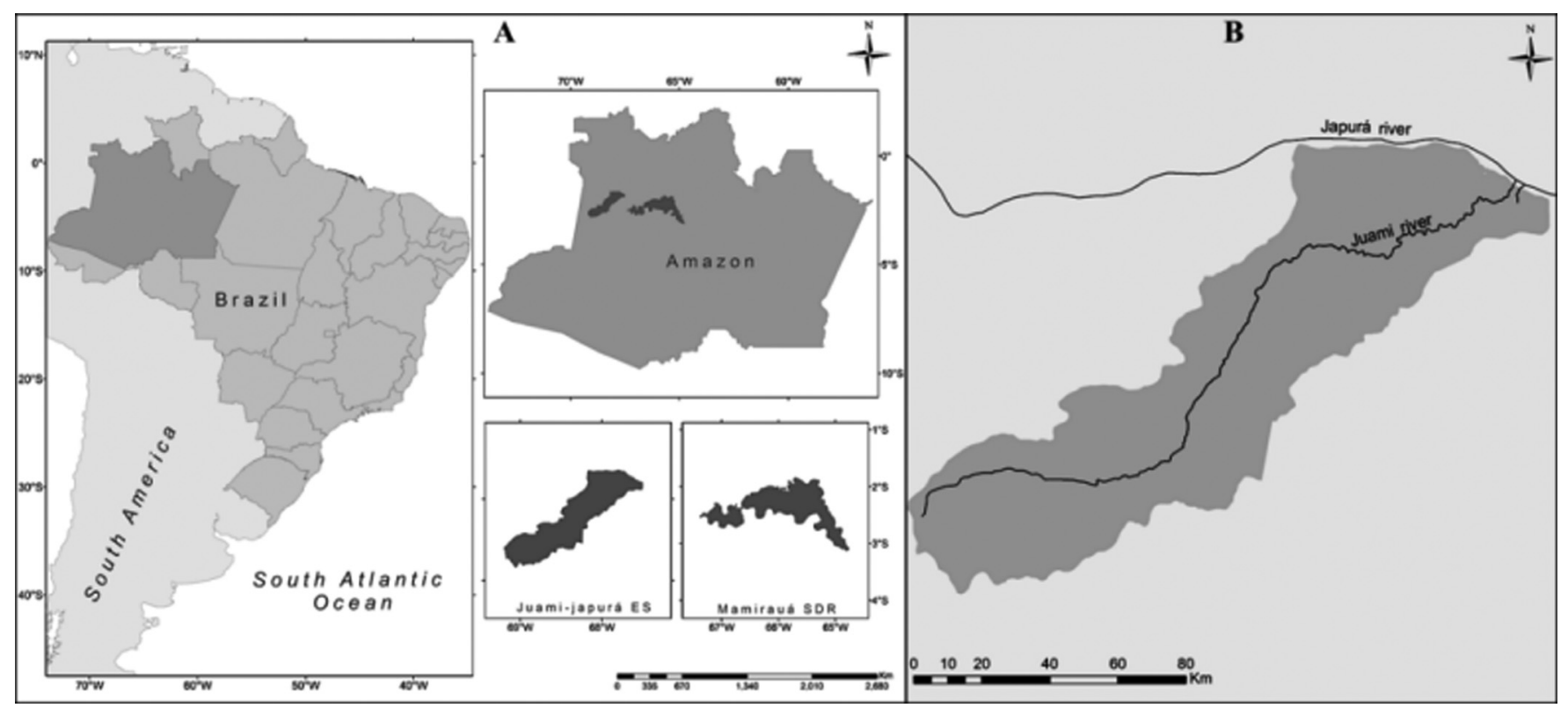

FIG. 1. (A) Study areas in Amazon: Juami-Japurá Ecological Station and Mamirauá Sustainable Development Reserve. (B) Juami and Japurá rivers paths.

have not been broadly studied for Amazon river dolphin from different areas. We aim to contribute to the understanding of the repertoire of this lesser-studied cetacean. This study specifically intends (1) to characterize the low frequency pulsed vocalizations of the Amazon river dolphin at the Juami-Japurá Ecological Station, (2) to document possible effects of water properties in the dolphins' acoustic behavior, and (3) to examine differences in acoustic parameters between two populations.

\section{METHODOLOGY}

\section{A. Study areas}

The Juami-Japurá Ecological Station (JJES) $\left(01^{\circ} 39^{\prime} \mathrm{S}\right.$, $68^{\circ} 02^{\prime} \mathrm{W}$ ) is a Brazilian conservation unit located between the interfluve of the Solimões river (the regional designation of that part of the Amazon) and the Japurá river. The JJES area is covered by dense upland ombrophilous tropical forests (Veloso et al., 1991) and the climate is the rainy tropical type (Af subgroup of the Köppen climate classification system). The dry season occurs from July to November (RADAMBRASIL, 1977).

The Mamirauá Sustainable Development Reserve (MSDR) $\left(03^{\circ} 20^{\prime} \mathrm{S}, 64^{\circ} 54^{\prime} \mathrm{W}\right)$ is situated in the confluence of the Japurá and Solimões rivers, which are two large "whitewater" (rich in sediments) rivers. The reserve is characterized by seasonally flooded forest (Junk, 1983). The weather is tropical humid and the dry season occurs from September to November (Ayres, 1993) (Fig. 1).

Abiotic attributes of the river waters were considered as possible factors in acoustic variation. Amazonian waters have traditionally been classified as white, black, or clear. Sioli (1984) showed that these waters are chemically and physically heterogeneous (Table I). White water rivers carry a high sediment load derived from their headwaters in the Andes. Black and clear water rivers have catchments confined within the Amazonian forest and carry little inorganic sediment (Schmidt, 1973; Devol et al., 1984; Junk and Piedade, 1993).

\section{B. Field sampling and spectrographic analysis}

Field sampling was carried out for three days (August 29 to 31, 2012), from 6:00 to 18:00. All recording sessions were performed on a drifting boat with the engine and depth sounder off. Once the animals were sighted, the recordings were carried out until they left the area.

The recording system was composed by a Cetacean Research C54XRS hydrophone positioned between 2 and $4 \mathrm{~m}$ deep $(+3 /-20 \mathrm{~dB},-185 \mathrm{~dB}$ re $1 \mathrm{~V} / \mu \mathrm{Pa})$ coupled to a digital Fostex FR-2 LE recorder sampling at $96 \mathrm{kHz} / 24$ bits. The analysis focused on the vocalizations that globally did not exceed the Nyquist frequency of the recording system, thus any aliasing effect was absent on the analyzed signals. The .wav files were analyzed through the spectrogram configured with a FFT length of 2048 samples, $60 \%$ overlap and Hamming window of 1024 points generated by software Raven Pro 1.5 (Cornell Laboratory of Ornithology, Cornell University, Ithaca, New York).

The selection of pulsed vocalizations was made based on their signal-to-noise ratio (SNR), which had to be sufficiently high (greater than $10 \mathrm{~dB}$ ) so that both time and frequency parameters could be clearly measured. The

TABLE I. Ecological attributes of water types (Sioli, 1984).

\begin{tabular}{lcc}
\hline \hline Abiotic attributes & White water & Black water \\
\hline $\mathrm{pH}$ & Near neutral & Acidic, $<5$ \\
Electric conductivity & $40-1000$ & $<20$ \\
Transparency (Secchi depth) & $20-60 \mathrm{~cm}$ & $60-120 \mathrm{~cm}$ \\
Water color & Turbid (muddy) & Brownish \\
Humic substances & Low & High \\
Inorganic suspensoid & High & Low \\
Density & High & Low \\
\hline \hline
\end{tabular}


vocalizations analyzed were grouped according to the number of pulses: multiple (composed by a series of pulses) or single (just one pulse). The following acoustic parameters were extracted from spectrograms: minimum, maximum, peak and center frequencies, bandwidth (maximum-minimum frequency), duration, number of pulses (just for multiple pulses vocalizations), production rate of pulses (pulses/ s), and number of harmonics. The emission rate was calculated by the following ratio: number of vocalizations/min/ number of sighted individuals.

The descriptive statistics-mean, standard deviation, minimum and maximum values-were calculated for each parameter.

\section{Effect of physical environment and differences between populations}

The analysis of possible physical environment effects took into consideration recordings conducted in either white or black water at JJES. Whereas for differences between populations study, it was considered recordings made just in white waters, both at JJES and MSDR.

The Wilcoxon test was performed using R 2.15.3 statistical software (R Core Team, 2013) to analyze the differences in acoustic parameters of vocalizations emitted in the two types of water. The same individuals were eventually recorded in the two water conditions, since they were seen moving freely between black and white waters. The distance between the animals and the boat was controlled in both water conditions, in order that the sampled animals were at a distance of up to $5 \mathrm{~m}$ from the boat, thus frequency attenuation was negligible. Descriptive statistics-mean, standard deviation, minimum and maximum values-were calculated for each parameter of vocalizations emitted in both water types.

A principal components analysis (PCA) of measured acoustical parameters was performed to examine the pattern of variability in both conditions of water turbidity. Acoustic features of vocalizations may be highly correlated with one another and the PCA should isolate independent and uncorrelated acoustic variables from the original set of ten extracted parameters.

In the differences between populations analysis, the JJES recordings were compared with results found by Podos et al. (2002) (Nyquist frequency of $15-18 \mathrm{kHz} ;-240$ to $-165 \mathrm{~dB}$ re $1 \mathrm{~V} / \mu \mathrm{Pa}$ ) and Rocha (2009) (Nyquist frequency of $150 \mathrm{kHz} ;-165 \mathrm{~dB}$ re $1 \mathrm{~V} / \mu \mathrm{Pa}$ ) in MSDR. These authors conducted the recordings in white water; therefore just recordings performed under the same type of water in JJES were considered, in order to minimize the environmental effects of water turbidity in the acoustic behavior. In addition, a comparison within MSDR population was performed as a control condition.

The comparisons between the two populations were performed by F-test, which tested the null hypothesis that the variances were equal, and then the t-test to test the null hypothesis of equal means (May-Collado and Wartzok, 2008). The level of significance adopted was $\alpha=0.05$.

\section{RESULTS}

\section{A. Acoustic characteristics of pulsed vocalizations}

During sampling the dolphin group size ranged from 1 to $4(2.25 \pm 1.09)$ animals. We analyzed 183 pulsed vocalizations in a total of $6 \mathrm{~h}, 18 \mathrm{~min}$, and $19 \mathrm{~s}$ of recordings. Vocalizations recorded were rapid emissions of frequencymodulated pulses emitted in series $(\mathrm{N}=143)$ or singly (single pulse: $\mathrm{N}=49$ ) (Fig. 2), both designs presented harmonic structure The emission rate was 0.09 vocalizations/min/number of sighted individuals. Descriptive parameters are presented in Table II.

\section{B. Effect of physical environment}

The Wilcoxon test showed significant differences between the two conditions of water turbidity for the following acoustic parameters: maximum frequency, center frequency, bandwidth, duration and number of harmonics were lower in white water, and production rate of pulses, higher in white water (Table III).

Principal component analysis generated nine statistically independent components for both water turbidity conditions. For white water the first three components accounted $77.21 \%$ of data variance, meaning that the complexity of the data set can be reduced to three components with a $22.79 \%$ loss of information. Table IV shows each component with its percent variances and the acoustic parameters correlated. All components were loaded negatively with acoustics variables. Component 1 was loaded with low, peak, and center frequencies. Component 2 was loaded with high frequency, bandwidth and number of harmonics. Component 3 was loaded with duration, number of pulses and production rate.

For black water the first three components accounted $82.39 \%$ of data variance, this could mean that the complexity of the data set can be reduced to three components with a $17.61 \%$ loss of information. Table $\mathrm{V}$ shows each component with its percent variances and the acoustic parameters correlated. Component 1 was loaded negatively with high frequency, duration, bandwidth and number of harmonics. Component 2 was loaded positively with low, peak and center frequencies. Component 3 was loaded positively with number of pulses and production rate.

The correlation circle generated by the PC analysis shows the proximity among the acoustic variables. For white water, the parameters low frequency (LF), center frequency $(\mathrm{CF})$, peak frequency $(\mathrm{PF})$, high frequency $(\mathrm{HF})$, bandwidth $(\mathrm{BW})$, number of harmonics $(\mathrm{NH})$, duration (D) and number of pulses (NP) were better represented, since they are close to the unit circle. HF, BW, and $\mathrm{NH}$ are correlated and independent from $\mathrm{CF}, \mathrm{PF}$, and LF, which are also correlated. The D and NP showed strongly correlation and are independent from other variables [Fig. 3(A)].

For black water HF, BW, NH, CF, PF, LF, D, NP, and PR were well represented. The parameter production rate (PR) was better represented than in the correlation circle for white water. $\mathrm{HF}, \mathrm{BW}$, and $\mathrm{NH}$ are strongly correlated and 

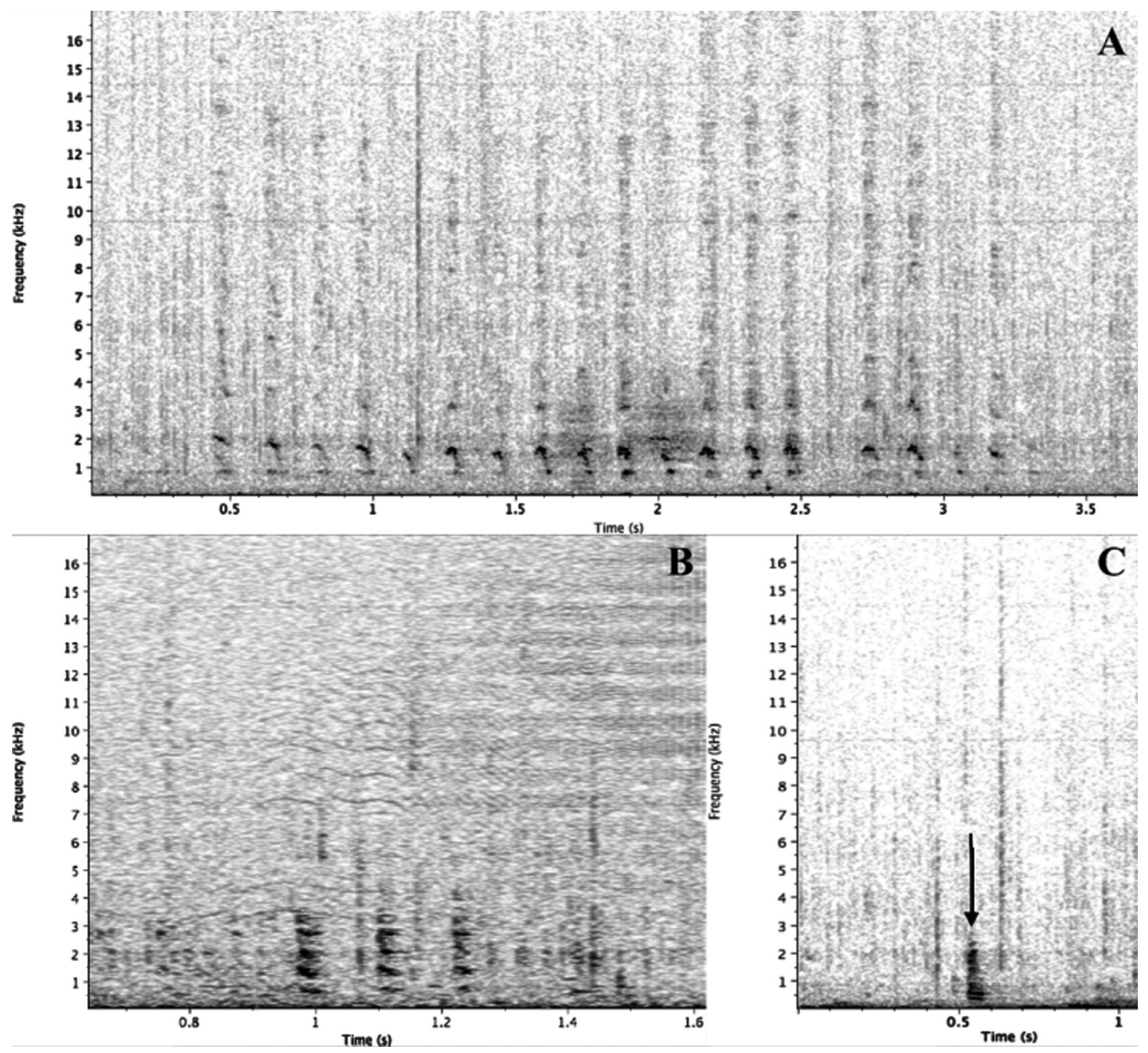

FIG. 2. Pulsed vocalizations of Amazon river dolphin (Spectrogram parameters: FFT length of 2048 samples, $60 \%$ overlap and Hamming window). (A) and (B) Multiple pulses (series of pulses). (C) The arrow points to a single pulse.

independent of the $\mathrm{CF}, \mathrm{LF}$ and $\mathrm{PF}$, also correlated between themselves. LF and PF also showed strongly correlation. The $\mathrm{D}$ and NP are correlated and independent from the other variables [Fig. 3(B)].

\section{Differences between populations}

Table VI presents means and standard deviations for measured vocalizations from JJES and MSDR populations.

TABLE II. Descriptive statistics of acoustic characteristics of Inia geoffrensis vocalizations from Juami-Japurá Ecological Station, Amazon, Brazil. (Values presented as mean $\pm \mathrm{SD}$ and range).

\begin{tabular}{lccc}
\hline \hline & Multiple pulses $(\mathrm{n}=134)$ & Single pulses $(\mathrm{n}=49)$ & Total $(\mathrm{n}=183)$ \\
\hline Minimum frequency $(\mathrm{kHz})$ & $0.52 \pm 0.24[0.06-1.39]$ & $0.64 \pm 0.34[0.12-1.39]$ & $0.52 \pm 0.24[0.06-1.39]$ \\
Maximum frequency $(\mathrm{kHz})$ & $3.37 \pm 2.88[1.67-17.10]$ & $2.88 \pm 1.73[1.76-12.35]$ & $3.37 \pm 2.88[1.67-17.10]$ \\
Peak frequency $(\mathrm{kHz})$ & $1.29 \pm 0.39[0.09-2.11]$ & $1.43 \pm 0.46[0.23-2.11]$ & $1.29 \pm 0.39[0.09-2.11]$ \\
Center frequency $(\mathrm{kHz})$ & $1.32 \pm 0.33[0.09-2.77]$ & $1.45 \pm 0.42[0.23-2.77]$ & $1.32 \pm 0.33[0.09-2.77]$ \\
Bandwidth $(\mathrm{kHz})$ & $2.85 \pm 2.87[0.85-16.62]$ & $2.25 \pm 1.62[0.85-11.14]$ & $2.85 \pm 2.87[0.85-16.62]$ \\
Duration $(\mathrm{s})$ & $0.26 \pm 0.35[0.03-2.49]$ & $0.06 \pm 0.04[0.03-0.22]$ & $0.26 \pm 0.35[0.03-2.49]$ \\
Number of pulses & $5.46 \pm 3.71[2.00-19.00]$ & 1.001 .00 & $4.27 \pm 3.74[1.00-19.00]$ \\
Production rate of pulses (pulses/s) & $21.40 \pm 8.48[4.36-37.31]$ & $19.13 \pm 8.08[4.65-40.00]$ & $20.79 \pm 8.44[4.36-40.00]$ \\
Number of harmonics & $3.30 \pm 1.60[1.00-8.00]$ & $3.00 \pm 1.54[1.00-9.00]$ & $3.22 \pm 1.59[1.00-9.00]$ \\
\hline \hline
\end{tabular}


TABLE III. Acoustic characteristics of Inia geoffrensis vocalizations in different conditions of water turbidity from Juami-Japurá Ecological Station and p- values of Wilcoxon test. Significant $p$ values are shown in bold. (Values presented as mean \pm SD and range).

\begin{tabular}{|c|c|c|c|}
\hline & White water (turbid) $(\mathrm{n}=98)$ & Black water (brownish) $(\mathrm{n}=85)$ & p-value \\
\hline Minimum frequency $(\mathrm{kHz})$ & $0.50 \pm 0.23[0.18-1.34]$ & $0.54 \pm 0.26[0.06-1.39]$ & 0.637 \\
\hline Maximum frequency $(\mathrm{kHz})$ & $2.33 \pm 0.50[1.67-5.09]$ & $4.56 \pm 3.87[1.76-17.10]$ & $<\mathbf{0 . 0 0 0 1}$ \\
\hline Peak frequency $(\mathrm{kHz})$ & $1.25 \pm 0.31[0.52-2.06]$ & $1.34 \pm 0.46[0.09-2.11]$ & 0.166 \\
\hline Center frequency $(\mathrm{kHz})$ & $1.26 \pm 0.23[0.80-1.97]$ & $1.40 \pm 0.41[0.09-2.77]$ & 0.007 \\
\hline Bandwidth (kHz) & $1.83 \pm 0.52[0.85-4.62]$ & $4.03 \pm 3.86[1.25-16.62]$ & $<\mathbf{0 . 0 0 0 1}$ \\
\hline Duration (s) & $0.18 \pm 0.12[0.03-0.58]$ & $0.36 \pm 0.48[0.03-2.49]$ & 0.017 \\
\hline Number of pulses & $4.60 \pm 3.38[1.00-16.00]$ & $3.88 \pm 4.09[1.00-19.00]$ & 0.084 \\
\hline Production rate of pulses (pulses/s) & $25.34 \pm 5.58[11.24-37.31]$ & $15.55 \pm 8.13[4.36-40.00]$ & $<\mathbf{0 . 0 0 0 1}$ \\
\hline Number of harmonics & $2.68 \pm 1.16[1.00-8.00]$ & $3.84 \pm 1.79[2.00-9.00]$ & $<0.0001$ \\
\hline
\end{tabular}

The t-test showed that minimum frequency, maximum frequency, peak frequency and duration of multiple pulses were lower for JJES population. No significant differences were found for numbers of harmonics and number of pulses. In relation to single pulses, the duration was significantly different between JJES and MSDR. The comparison within MSDR population (Podos et al., 2002; Rocha, 2009) did not show significant differences for available parameters duration and number of pulses (Table VII).

\section{DISCUSSION}

\section{A. Acoustic characteristics of pulsed vocalizations}

The vocalizations recorded either contained single or multiple pulses and presented harmonic structure. Podos et al. (2002) also found the same types. Most of our recordings presented multiple pulses $(\mathrm{N}=134)$, Podos et al. (2002) also observed most vocalizations containing multiple pulses (designated by them as notes) $(\mathrm{N}=216)$.

Other studies recorded these pulsed signals for Amazon river dolphins. Caldwell and Caldwell (1970) observed these vocalizations (which they called "squeals") consisting of a series of pulses, during transportation of two individuals for a "Sea World" in Los Angeles. Diezgranados and Trujilo (2002) recorded these emissions for two populations in the Orinoco river basin at Colombia.

TABLE IV. Principal components analysis (PCA) loadings of acoustic parameters for white water, their eigenvalues and their percent variance explained for pulsed vocalizations prodiced by Amazon river dolphins. High loadings (>absolute 0.30 ) are highlighted in bold for each component (PC).

\begin{tabular}{lrrr}
\hline \hline & \multicolumn{1}{c}{ PC1 } & PC2 & \multicolumn{1}{c}{ PC3 } \\
\hline Low frequency & $\mathbf{- 0 . 4 7 2 1 4 5 3 3 7}$ & -0.183588 & -0.22093725 \\
High frequency & 0.126262856 & $\mathbf{- 0 . 6 1 4 1 9 7 6 3}$ & 0.07352735 \\
Peak frequency & $-\mathbf{0 . 3 9 1 8 8 4 2 2 3}$ & -0.28491097 & -0.18673492 \\
Duration & 0.349690306 & 0.02659087 & $-\mathbf{0 . 5 2 7 6 6 4 0 9}$ \\
Center frequency & $\mathbf{- 0 . 4 1 2 9 8 0 0 6 6}$ & -0.33067891 & -0.28878499 \\
Bandwidht & 0.325356746 & $\mathbf{- 0 . 5 0 4 9 0 4 4 1}$ & 0.16523445 \\
Number of pulses & 0.340221298 & 0.03617269 & $-\mathbf{0 . 5 9 3 6 1 0 2 9}$ \\
Number of harmonics & 0.305023634 & $-\mathbf{0 . 3 7 5 0 7 4 7 4}$ & 0.09920811 \\
Production rate & 0.008967804 & -0.03014725 & $-\mathbf{0 . 3 9 9 4 5 7 7 9}$ \\
\% of variance & 31.38 & 25.34 & \multicolumn{1}{c}{20.49} \\
Cumulative \% & 31.37 & 56.72 & \multicolumn{1}{c}{77.21} \\
\hline \hline
\end{tabular}

Although this species is mostly solitary, temporary aggregations may be formed in foraging contexts. Podos et al. (2002) observed the described vocalizations during foraging behavior, when such pulsed signals possibly occurred. Besides that, pulsed emissions are associated with relations of proximity among individuals, as in agonistic interactions among males for access to females (Herzing, 2000).

Burst-pulses sounds in general are not well studied, although they seem to have a predominatly communicative function (Herman and Tavolga, 1980). It would be important to know more about these emissions in the various odontocete species, in different environments and activities.

\section{B. Effect of physical environment}

Characteristics of acoustic signals are affected by environmental conditions, hence communication mechanisms have evolved to adapt to different abiotic conditions (Morton, 1975; Wiley and Richards, 1978; Sugiura et al., 1999).

Our results revealed that frequency and temporal structures of pulsed vocalizations of the Amazon river dolphin, changed in relation to the abiotic conditions of water turbidity. Since the target animals were at a distance of up to $5 \mathrm{~m}$ from the boat, and consequently the frequency attenuation was negligible, the observed differences between the two conditions of water resulted from a change in the acoustic behavior on the part of the animals.

TABLE V. Principal components analysis (PCA) loadings of acoustic parameters for black water, their eigenvalues and their percent variance explained for pulsed vocalizations prodiced by Amazon river dolphins. High loadings ( $>$ absolute 0.30 ) are highlighted in bold for each component (PC).

\begin{tabular}{lrcr}
\hline \hline & PC1 & PC2 & \multicolumn{1}{c}{ PC3 } \\
\hline Low frequency & 0.1924846 & $\mathbf{0 . 4 7 3 7 5 2 6 3}$ & 0.1151421 \\
High frequency & $-\mathbf{0 . 4 2 9 5 9 2 8}$ & 0.29368068 & -0.1600795 \\
Peak frequency & 0.1862886 & $\mathbf{0 . 4 9 6 4 2 0 0 5}$ & 0.0843992 \\
Duration & $\mathbf{- . 4 5 1 8 4 0 4}$ & -0.07211979 & 0.4146143 \\
Center frequency & 0.0545982 & $\mathbf{0 . 5 4 9 0 4 7 6}$ & 0.1764814 \\
Bandwidht & $\mathbf{- 0 . 4 4 3 6 1 2 4}$ & 0.26256534 & -0.1682912 \\
Number of pulses & -0.3474042 & -0.1007463 & $\mathbf{0 . 6 7 3 8 2 3 7}$ \\
Number of harmonics & $\mathbf{- 0 . 3 2 3 1 1 4 4}$ & 0.21923466 & $-\mathbf{0 . 2 2 3 0 6 2 5}$ \\
Production rate & 0.3386311 & 0.09522865 & $\mathbf{0 . 4 6 7 7 8 8 2}$ \\
\% of variance & 39.55 & 30.57 & 12.27 \\
Cumulative \% & 39.55 & 70.12 & 82.39 \\
\hline \hline
\end{tabular}



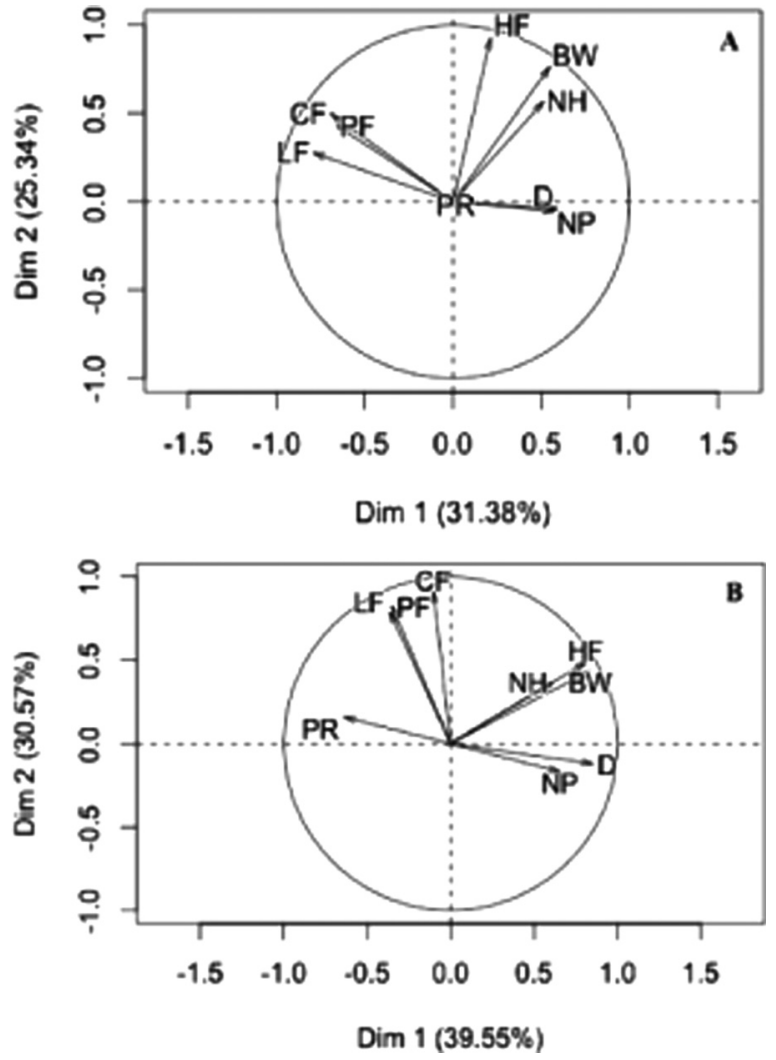

FIG. 3. Correlation circle of Principal Component Analysis showing the position of acoustic parameters in the two-dimensional spaces (Dim) of the two principal components. (A) White water; (B) black water. $\mathrm{LF}=$ low frequency; $\mathrm{HF}=$ high frequency; $\mathrm{CF}=$ center frequency; $\mathrm{PF}=$ peak frequency; $\mathrm{BW}=$ bandwidth; $\mathrm{NH}=$ number of harmonics; $\mathrm{NP}=$ number of pulses; $\mathrm{D}=$ duration; $\mathrm{PR}=$ production rate of pulses.

White water presents much higher quantities of particles in suspension than black water (Sioli, 1956). Signals emitted in rich sediments water (white water) have more attenuation and geometric spreading along their propagation (Stoll, 1985; Kibblewhite, 1989; Bradley and Stern, 2008). The scattering process is also higher in this water type, since sound energy bends as soon as it hits a particle (diffraction) (Medwin, 2005). The maximum frequency, center frequency, bandwidth and number of harmonics were significantly lower in white water than black water. Considering that lower frequencies present greater wavelength, this emission change would ensure that acoustic information is reliably transmitted and increases the active space of the signal under conditions of higher attenuation, spreading and scattering (Hamilton, 1980).

Vocalizations should be heard by nearby animals (Smith, 1996; Lammers et al., 2003) thus, any possibly losses would affect any messages encoded. The lower value of duration, higher production rate and higher emission rate in white water, may be an adaptation to the propagation conditions. The abiotic condition of black water enables emission with higher duration, lower production rates and lower vocalizations per minute per number of individuals. Since this type of water permits better sound propagation and allows somewhat better visibility, the animals may invest less in their emissions.

After data reduction through PCA, the vocalizations required three main structural components for white water and black water to be described reasonably. As showed in the correlation circle, different water conditions lead to different grouped and restricted frequency parameters. Low frequency, center frequency and peak frequency are independent from high frequency and bandwidth. It is not surprising that high frequency, bandwidth and number of harmonics are associated, since the highest frequency is dependent on the number of harmonics within the vocalization, which also occurred for duration and number of pulses.

Moreover, the PCA showed that Amazon river dolphins modulate the extracted acoustics parameters in different water conditions. High frequency, number of harmonics and bandwidth are more correlated in black water than white water. Besides that, peak frequency and low frequency are strongly correlated in black water, whereas in white water the peak frequency is strongly correlated with center frequency. In addition, the parameters duration, number of pulses and production rate are best represented in the correlation circle of black water. It is likely that these variables carry additional information and may be used by animals in this low-sediment condition water.

\section{Differences between populations}

Acoustic geographic variations may be viewed as results of adaptations to differences in environmental conditions or

TABLE VI. Means and standard deviations for measured vocalizations emitted by Amazon river dolphin (Inia geoffrensis) from Juami-japurá Ecological Station in comparison with other studies.

\begin{tabular}{|c|c|c|c|c|c|c|c|c|}
\hline & \multicolumn{6}{|c|}{ Multiple pulses } & \multirow{2}{*}{$\begin{array}{l}\text { Single pulses } \\
\text { Duration (s) }\end{array}$} & \multirow[b]{2}{*}{ Source } \\
\hline & $\begin{array}{c}\text { Minimum } \\
\text { frequency }(\mathrm{kHz})\end{array}$ & $\begin{array}{c}\text { Maximum } \\
\text { frequency }(\mathrm{kHz})\end{array}$ & $\begin{array}{l}\text { Peak frequency } \\
\qquad(\mathrm{kHz})\end{array}$ & $\begin{array}{l}\text { Number of } \\
\text { harmonics }\end{array}$ & $\begin{array}{l}\text { Duration } \\
\text { (s) }\end{array}$ & $\begin{array}{l}\text { Number } \\
\text { of pulses }\end{array}$ & & \\
\hline Mean & 0.5 & 2.33 & 1.25 & 2.68 & 0.18 & 4.6 & 0.05 & $\begin{array}{c}\mathrm{n}=98 \text { - Juami-japurá Ecological Station, } \\
\text { Amazon, Brazil (This study). }\end{array}$ \\
\hline SD & 0.23 & 0.5 & 0.31 & 1.16 & 0.12 & 3.38 & 0.01 & \\
\hline Mean & - & - & - & - & 0.72 & 4.18 & 0.10 & $\begin{array}{c}\mathrm{n}=240 \text { - Mamirauá Reserve, Amazon, } \\
\text { Brazil (Podos et al., 2002) }\end{array}$ \\
\hline SD & & & & & 0.45 & 2.35 & 0.07 & \\
\hline Mean & 1.3 & 17.0 & 3.1 & 3.5 & 0.79 & 3.3 & - & $\begin{array}{c}\mathrm{n}=39 \text { - Mamirauá Reserve, Amazon, } \\
\text { Brazil (Rocha, 2009) }\end{array}$ \\
\hline SD & 1.1 & 7.5 & 2.9 & 4.6 & 0.81 & 4.0 & & \\
\hline
\end{tabular}


TABLE VII. Pairwise comparisons of Inia geoffrensis pulsed vocalizations parameters obtained in this study with results presented in available literature. Significant $\mathrm{p}$ - values are shown in bold.

\begin{tabular}{|c|c|c|c|c|c|c|}
\hline \multirow[b]{3}{*}{ Multiple pulses } & \multicolumn{6}{|c|}{ Populations } \\
\hline & \multicolumn{2}{|c|}{ JJES and MSDR (Rocha, 2009) } & \multicolumn{2}{|c|}{ JJES and MSDR (Podos et al., 2002) } & \multicolumn{2}{|c|}{ MSDR (Rocha, 2009) and (Podos et al., 2002) } \\
\hline & $\mathrm{t}$ Test & p-value & $\mathrm{t}$ Test & p-value & $\mathrm{t}$ Test & p-value \\
\hline Minimum frequency $(\mathrm{kHz})$ & -4.503 & $<0.0001$ & - & - & - & - \\
\hline Maximum frequency $(\mathrm{kHz})$ & -12.204 & $<\mathbf{0 . 0 0 0 1}$ & - & - & - & - \\
\hline Peak frequency $(\mathrm{kHz})$ & -3.975 & 0.0003 & - & - & - & - \\
\hline Number of harmonics & -1.099 & 0.278 & - & - & - & - \\
\hline Duration (s) & -4.683 & $<0.0001$ & -17.156 & $<0.0001$ & -0.527 & 0.601 \\
\hline Number of pulses & 1.926 & 0.056 & 1.124 & 0.262 & 1.337 & 0.188 \\
\hline \multicolumn{7}{|l|}{ Single pulses } \\
\hline Duration (s) & - & - & -10.799 & $<0.0001$ & - & - \\
\hline
\end{tabular}

be a by-product due to the isolation and genetic divergence among populations (Ford, 1991; Foster and Cameron, 1996).

Our recordings and those made by Podos et al. (2002) and Rocha (2009) were carried out in the dry season with the same water turbidity and seasonal rivers dynamics. Pairwise comparisons showed significant differences in both frequency and time parameters, which may indicate geographic variation between populations. Frequency parameters presented lower means in emissions recorded in JJES than those recorded in MSDR. Differences in frequency parameters are usually associated with variation between species or between populations and are generally related to anatomical variables such as body size or noise levels conditions (see Rendell et al., 1999).

Temporal parameter (duration) was also significantly different between populations. Differences in duration were also documented for whistles of Hawaiian spinner dolphin (Bazúa-Durán and Au, 2004) and Tursiops truncatus (Janik et al., 1994; Wang et al., 1995), and could be associated with different individuals engaged in different activities during the recording sessions. The comparison of duration parameter between the same population in MSDR-Podos et al. (2002) vs Rocha (2009)—could be considered as a control condition for supporting the geographic variation, since no significant difference was observed.

Different group sizes may have significant influence in the sound emission of the animals and thus, can be another factor to explain the geographic variation (Norris et al., 1994; Herzing, 2000). In this study, Inia geoffrensis group size ranged from 1 to 4 individuals, while in the work of Rocha (2009), it ranged from 1 to 15 and for Podos et al. (2002) it was from 1 to 14 individuals. Therefore, the variation of acoustics parameters may reflect the isolation of populations, behavior context and adaptation to the environmental conditions (other than turbidity) such as shape, depth and geology of rivers, temperature of water, underwater vegetation density and noise levels. Thus, understanding differences in signaling of distinct populations requires a variety of multidisciplinary approaches.

\section{CONCLUSIONS}

This is the first work to describe pulsed vocalizations signals of Amazon river dolphin in the Juami-Japurá Ecological
Station. Repertoire characteristics may provide baseline information for further approaches concerning differences between populations, acoustic ecology, taxonomy, and behavior studies.

Abiotic underwater features play an important role in the process of communication system. The variation of acoustic parameters in different conditions of water turbidity demonstrates that these aspects of the animals' acoustic behavior might be sensitive to abiotic features of their environment. More observational and experimental studies are needed to determine how pervasive the effect of turbidity is upon vocalizations characteristics and they should include qualitative and quantitative analysis of other pulsed vocalizations emitted by Amazon river dolphins.

\section{ACKNOWLEDGMENTS}

We thank Instituto Chico Mendes de Conservação da Biodiversidade for financial support and Júlio César Rocha Costa for administrative and fieldwork support and incentive in performing this research. We are also grateful to Postgraduate Program in Ecology, as well as the Research Laboratory of Behavioral Ecology and Bioacoustics (LABEC) - UFJF and Instituto Aqualie for supporting this study and providing the recording equipment. Manuel E. dos Santos was supported by Fundação para a Ciência e Tecnologia (FCT), through the strategic project UID/MAR/ 04292/2013 granted to MARE. Two anonymous reviewers greatly contributed to improve the manuscript.

Au, W. W. L., and Hastings, M. C. (2008). Principles of Marine Bioacoustics (Springer, New York, NY), Chap. 9, pp. 337-400.

Ayres, J. M. C. (1993). As Matas de Várzea do Mamirauá ("The Lowland Forests in Mamirauá") (MCT-CNPq Sociedade civil de Mamirauá, Brasil), Programa do trópico úmido. 127 pp.

Azzolin, M., Papale, E., Lammers, M. O., Gannier, A., and Giacoma, C. (2013). "Geographic variation of whistles of the striped dolphin (Stenella coeruleoalba) within the Mediterranean Sea," J. Acoust. Soc. Am. 134, 694-705.

Bazúa-Durán, C., and Au, W. W. L. (2004). "Geographic variations in the whistles of spinner dolphins (Stenella longirostris) of the main Hawai'ian Islands," J. Acoust. Soc. Am. 116, 3757-3769.

Bradbury, J. W., and Vehrencamp, S. L. (1998). Principles of Animal Communication (Sinauer, Sunderlands, MA), Chap.3, pp. 65-112.

Bradley, D. L., and Stern, R. (2008). Underwater Sound and the Marine Mammal Acoustic Environment: A Guide to Fundamental Principles 
(U. S. Marine Mammal Commission, Bethesda, MD), Chap. 4, pp. 35-46.

Caldwell, M. C., and Caldwell, D. K. (1967). Intra-specific Transfer of Information Via the Pulsed Sound in Captive Odontocete Cetaceans. Animal Sonar Systems, edited by R. G. Busnel (Jouy en Josas, France), pp. 879-936.

Caldwell, M. C., Caldwell, D. K., and Evans, W. E. (1966). "Sounds and behavior of captive Amazon freshwater dolphin, Inia geoffrensis," Mus. Cont. Sci. 108, 1-24.

Conner, D. S. (1982). "Dialects versus geographic variation in mammalian vocalizations," Anim. Behav. 30, 297-298.

Deecke, V. B., Ford, J. K. B., and Spong, P. (1999). "Quantifying complex patterns of bioacoustic variation: Use of a neural network to compare killer whale (Orcinus orca) dialects," J. Acoust. Soc. Am. 105, 2499-2507.

Devol, A. H., Zaret, T. M., and Forsberg, B. R. (1984). "Sedimentary organic matter diagenesis and its relation to the carbon budget of tropical floodplain lakes,” Verh. Internat. Verein Limnol. 22, 1299-1304.

Diezgranados, M. C., and Trujillo, F. (2002). "Vocal repertoire of the freshwater dolphin Inia geoffrensis and Sotalia fluviatilis on Colombia, South America," J. Acoust. Soc. Am. 112, 2400.

Ding, W., Würsig, B., and Evans, W. (1995). "Comparisons of whistles among seven odontocete species," in Sensory Systems of Aquatic Mammals, edited by R. A. Kastelein, J. A. Thomas, and P. E. Nachtigall (De Spil Publishers, Woerden, The Netherlands), pp. 299-323.

Ding, W., Würsig, B., and Leatherwood, S. (2001). "Whistles of boto, Inia geoffrensis, and tucuxi, Sotalia fluviatilis," J. Acoust. Soc. Am. 109, 407-411.

Evans, W. E. (1973). "Echolocation by marine delphinids and one species of fresh-water dolphin," J. Acoust. Soc. Am. 54, 191-199.

Ford, J. K. B. (1991). "Vocal traditions among resident killer whales (Orcinus orca) in coastal waters of British Columbia," Can. J. Zool. 69, 1454-1483.

Ford, J. K. B. (2002). "Dialects," in The Encyclopedia of Marine Mammals, edited by W. F. Perrin, B. Würsig, and J. G. M. Thewissen (Academic, New York, NY), pp. 322-323.

Foster, S. A., and Cameron, S. A. (1996). "Geographic variation in behavior: A phylogenetic framework for comparative studies," in Phylogenies and the Comparative Method in Animal Behavior (Oxford University Press, New York, NY), pp. 138-165.

Grimes, L. G. (1974). "Dialects and geographical variation in the song on the splendid sunbird Nectarinia coccinigaster," Ibis 116, 314-329.

Hamilton, E. L. (1980). "Geoacoustic modeling of the sea floor," J. Acoust. Soc. Am. 68, 1313-1340.

Herman, L. M., and Tavolga, W. N. (1980). "The communication systems of cetaceans," in Cetacean Behavior (John Wiley and Sons, New York, NY), pp. 149-209.

Herzing, D. (2000). "Acoustics and social behavior of wild dolphins: Implications for sound society," in Hearing by Whales and Dolphins (Springer, New York, NY), pp. 225-272.

Janik, V. M., Dehnhardt, G., and Todt, D. (1994). "Signature whistle variation in the bottlenosed dolphin, Tursiops truncatus," Behav. Ecol. Sociobiol. 35, 243-248.

Junk, W. J. (1983). "Wetlands of tropical South America," in Wetlands of the World (Kluwer Publishers, The Netherlands), pp. 679-739.

Junk, W. J., and Piedade, M. T. F. (1993). "Biomass and primary-production of herbaceous plant communities in the Amazon floodplain," Hydrobiol. 263, 155-162.

Kamminga, C. (1979). "Remarks on dominant frequencies of cetacean sonar," Aquat. Mamm. 7, 93-100.

Kamminga, C., van Hove, M. T., Engelsma, F. J., and Terry, R. P. (1993). "Investigations on cetacean sonar X: A comparative analysis of underwater echolocation clicks of Inia spp. and Sotalia spp.," Aquat. Mammal. 19, 31-43.

Kibblewhite, A. C. (1989). "Attenuation of sound in marine sediments: A review with emphasis on new low-frequency data," J. Acoust. Soc. Am. 86, 716-738.

Krebs, J. R., and Kroodsma, D. E. (1980). "Repertoires and geographical variation in bird songs," Adv. Stud. Behav. 11, 143-177.

Lammers, M. O., Au, W. L. A., and Harzing, D. L. (2003). "The broadband acoustic signaling behavior of spinner and apoted dolphins," J. Acoust. Soc. Am. 114, 1629-1639.

Lemon, R. E. (1966). "Geographic variation in the song of cardinals," Can. J. Zool. 44, 413-428.
Lugli, M., and Fine, M. L. (2003). "Acoustic communication in two freshwater gobies: Ambient noise and short-range propagation in shallow streams," J. Acoust. Soc. Am. 114, 512-521.

Marler, P. (1960). "Bird songs and mate selection," in Animal Sounds and Communication, Publication 7, edited by W. E. Lanyon and W. N. Tavolga (American Institute of Biological Sciences, Washington, DC), pp. 348-367.

May-Collado, L. J., and Wartzok, D. (2007). "The freshwater dolphin Inia geoffrensis produces high frequency whistle,” J. Acoust. Soc. Am. 121, 1203-1212.

May-Collado, L. J., and Wartzok, D. (2008). "A comparison of bottlenose dolphin whistles in the Atlantic Ocean: Factors promoting whistle variation," J. Mammal. 89, 1229-1240.

McGregor, P. K., Peake, T. M., and Gilbert, G. (2000). "Communication, behaviour, and conservation," in Behaviour and Conservation, edited by L. M. Gosling and W. J. Sutherland (Cambridge University Press, New York, NY), pp. 261-285.

Medwin, H. (2005). Sounds in the Sea: From Ocean Acoustics to Acoustical Oceanography (Cambridge University Press, New York, NY), Chap. 1, pp. 50-85.

Miller, P. J. O., and Bain, D. E. (2000). "Within-pod variation in killer whale calls," Anim. Behav. 60, 617-628.

Morisaka, T., Shinohara, M., Nakahara, F., and Akamatsu, T. (2005). "Geographic variations in the whistles among three Indo-Pacific bottlenose dolphin Tursiops aduncus populations in Japan," Fisheries Sci. 71, 568-576.

Morton, E. S. (1975). "Ecological sources of selection on avian sounds," Am. Nat. 109, 17-34.

Mundinger, P. C. (1982). "Microgeographic and macrogeographic variation in the acquired vocalizations of birds," in Acoustic Communication in Birds: Song Learning and Its Consequences, edited by D. E. Kroodsma, E. H. Miller, and H. Ouellet (Academic, San Diego, CA), Vol. 2, pp. 147-208.

Norris, K. S., Harvey, G. W., Burzell, L. A., and Kartha, T. D. K. (1972). "Sound production in the freshwater porpoises Sotalia fluviatilis Gervais and Deville and Inia geoffrensis Blainville, in the Rio Negro, Brazil," Invest. Cetacea. 4, 251-260.

Norris, K. S., Wursig, B., Wells, R. S., and Wursig, M. (1994). The Hawaiian Spinner Dolphin (University of California Press, Berkeley, CA), $408 \mathrm{pp}$.

Penner, R. H., and Murchison, A. E. (1970). "Experimentally demonstrated echolocation in the Amazon River porpoise, Inia geoffrensis (Blainville)," Proc. 7th Ann. Conf. Biol. Sonar Diving Mammals. 7, 1-22.

Podos, J., da Silva, V. M. F., and Rossi-Santos, M. R. (2002). "Vocalizations of Amazon river dolphins, Inia geoffrensis: Insights into the evolutionary origins of delphinid whistles," Ethol. 108, 601-612.

RADAMBRASIL (1977). Geologia, geomorfologia, pedologia, vegetação e uso potencial da terra (Geology, geomorphology, soil conditions, vegetation and potential land use) (DNPM-Ministério das Minas e Energia (Rio de Janeiro, Brazil), 452 p.

$\mathrm{R}$ Core Team (2013). R: A Language and Environment for Statistical Computing (R Team, Vienna, Austria).

Rendell, L. E., Matthews, J. N., Gill, A., Gordon, J. C. D., and Macdonald, D. W. (1999). "Quantitative analysis of tonal calls from five odontocete species, examining interspecific and intraspecific variation,” J. Zool. 249, 403-410.

Rocha, J. V. A. (2009). "Caracterização das vocalizações da espécie Inia geoffrenis (Blainville, 1817) (Cetacea, Odontoceti) na Reserva de Desenvolvimento Sustentável Mamirauá, Amazônia Central (Characterization of vocalizations of the species Inia geoffrenis [Blainville, 1817] [Cetacea, Odontoceti] in the Mamiraua Sustainable Development Reserve, Central Amazon)," Masters dissertation, Universidade Federal de Juiz de Fora, MG, Brazil) 44 pp.

Schmidt, G. W. (1973). "Primary production of phytoplankton in the three types of Amazonian waters. The limnology of a tropical flood-plain lake in central Amazonia (Lago do Castanho)," Amazoniana 4, 139-203.

Sioli, H. (1956). "Über Natur und Mensch im brasilianischen Amazonasgebiet (About Nature and Man in the Brazilian Amazon)," Erdkunde. 10, 89-109.

Sioli, H. (1984). "The Amazon and its Main Effluents: Hydrography, Morphology of the River Courses, and River Types," in The Amazon, Limnology and Landscape Ecology of a Mighty Tropical River and Its Basin, edited by H. Sioli (Dr. W. Junk Publishers, Dordrecht, Netherlands), pp. 127-166. 
Smith, W. J. (1996). "Using interactive playback to study how songs and singing contribute to communication about behavior," in Ecology and evolution of acoustic communication in birds, edited by D. E. Kroodsma and E. H. Miller (Cornell University Press, Ithaca, NY), pp. 377-397.

Stafford, K. M., Nieukirk, S. L., and Fox, C. G. (2001). "Geographic and seasonal variation of blue whale calls in the North pacific," J. Cetacean Res. Manage. 3, 65-76.

Stoll, R. D. (1985). "Marine sediment acoustics," J. Acoust. Soc. Am. 77, 1789-1799.

Sugiura, H., Tanaka, T., and Masataka, N. (1999). "Sound transmission in the habitats of Japanese macaques and its effect on populational differences in coo calls (in Japanese)," J. Acoust. Soc. Jpn. 55, 679-687.

Veloso, H. P., Rangel Filho, A. L. R., and Lima, J. C. A. (1991). Classificação da Vegetação Brasileira, Adaptada a um Sistema Universal (Brazilian Vegetation Classification, Adapted to a Universal System) (IBGE, Rio de Janeiro, Brazil), http://www.ambientebrasil.com.br/composer.php3?base=./ natural/index.html\&conteudo=./natural/fitoeco.html.

Verfuss, U. K., Garcia-Hartman, M., and Schnitzer, H. U. (1997). "Hunting and echolocation behavior of a captive Amazon river dolphin (Inia geoffrensis)," in Proceeding of the Tenth Annual Conference of European Cetacean Society, edited P. G. H. Evans, Lisboa, Portugal (11-13 March), p. 102.
Wang, D., Wursig, B., and Evans, W. (1995). "Whistles of bottlenose dolphins: Comparison among populations," Aquat. Mamm. 21, 65-77.

Weilgart, L., and Whitehead, H. (1997). "Group-specific dialects and geographical variation in coda repertoire in South Pacific sperm whales," Behav. Ecol. Sociobiol. 40, 277-285.

Whitehead, H., Dillon, M., Dufault, S., Weilgart, L., and Wright, J. (1998). "Non-geographically based population structure of south Pacific sperm whales: Dialects, fluke-markings and genetics," J. Anim. Ecol. 67, 253-262.

Wiersma, H. (1982). "A comparison of wave shapes of odontocete sonar signals,” Aquat. Mamm. 9, 57-66.

Wiley, R. H., and Richards, D. G. (1978). "Physical constraints on acoustic communication in the atmosphere: Implications for the evolution of animal vocalizations," Behav. Ecol. Sociobiol. 3, 69-94.

Wiley, R. H., and Richards, D. G. (1982). "Adaptations for acoustic communication in birds: Sound transmission and signal detection," in Acoustic Communication in Birds, edited by D. E. Kroodsma and E. H. Miller (Academic Press, San Diego, CA), pp. 131-278.

Yurk, H., Barrett-Lennard, L., Ford, J. K. B., and Matkin, C. O. (2002). "Cultural transmission within maternal lineages: Vocal clans in resident killer whales in southern Alaska," Anim. Behav. 63, 1103-1119. 